2019 Global Fashion Management Conference at Paris Proceedings: 819-823 (July 2019) https://doi.org/10.15444/GFMC2019.08.05

\title{
HOW ATMOSPHERIC CUES IN A VIRTUAL REALITY FASHION STORES AFFECT THE SENSE OF PRESENCE
}

\author{
Maria Crespo, Instituto Universitário de Lisboa (ISCTE-IUL), Business Research \\ Unit (BRU-IUL), Portugal \\ Sandra Maria Correia Loureiro, Instituto Universitário de Lisboa (ISCTE-IUL), Business \\ Research Unit (BRU-IUL), Portugal ${ }^{1}$ \\ Ricardo Godinho Bilro, Instituto Universitário de Lisboa (ISCTE-IUL), Business Research \\ Unit(BRU-IUL), Portugal \\ João Guerreiro, Instituto Universitário de Lisboa (ISCTE-IUL), Business Research \\ Unit (BRU-IUL), Portugal
}

\begin{abstract}
Introduction

Virtual Reality is characterized by its levels of Immersion in a new world (e.g., Eroglu et al., 2001; Bhatt, 2004). Immersion is strongly related to the concept of flow, since involves a psychological state of isolation from the real world (Witmer \& Singer, 1998; Bhatt,2004). This is strongly related to the concept of Flow. Thus, a total sense of involvement of a consumer in a certain experience exists, resulting in an experience unlike any other, and without unexpected distractions (Nah, Eschenbrenner \& DeWester, 2011; Loureiro et al., 2018). Indeed, Mikropoulos (2006) claims that immersion causes a feeling of total presence (telepresence). However, there is a gap in literature liked to the lack of studies dealing with the way atmospheric cues of the fashion store influences presence. By atmospheric cues intended as "the conscious designing of space to create certain buyer effects" (Kotler, 1974, p. 50). The definition reflects the effort of creating retail environments that are intended to produce certain emotional effects on the buyer. Emotions that could develop and intensify the sense of presence. Thus, the aim of the current study is to explore how atmospheric cues in virtual reality fashion stores affect the sense of presence.
\end{abstract}

\section{Theoretical Background}

Kotler (1974) defines an intentional structure of perceived stimuli by consumers as Atmospherics. This term refers to a study of atmospheric variables and its effects on consumer behavior (Milliman and Fugate, 1993). After the pioneer contributes of Kotler (1974), Donovan and Rossiter (1982) and others have dedicated themselves to the study of atmospheric variables, such as color (Bellizzi \& Hite, 1992), scent (Mattila \& Wirtz, 2001; Michon, Chebat, \& Turley, 2005; Spangenberg, Crowley \& Henderson, 1996), light (Areni \& Kim, 1993), and music (e.g., Areni, 2003; Mattila \& Wirtz, 2001). These studies evolve for online context, but all them point out that the consumer is affected by stimuli created by the atmospheric cues, which conduct to emotions and behavioral intentions (e.g., Loureiro, Almeida, \& Rita, P. 2013. Loureiro, Koo, \& Ribeiro, 2013; Loureiro \& Roschk, 2014; Roschk, Loureiro, \& Breitsohl, 2017). Yet, literature is not prolifera in explaining how atmospheric cues in virtual world could operate to affect presence.

Cognitive appraisal theory reclaim that consumers have their own personal interpretation of an event. The primary appraisal is cognitive because individuals tend

\footnotetext{
${ }^{1}$ sandramloureiro@netcabo.pt
} 
to think about the event. In the secondary appraisal, individuals cope emotionally with the situation (Lazarus, 1991; Smith \& Kirby, 2009). Based on cognitive appraisal theory we may claim that a virtual reality store may create the event to be appraisal by retail visitors. The virtual reality event is an escapism experience inducing thoughts about the virtual store and also inducing the feeling of dominance (the feeling of being in control during the experience). The secondary appraisal could be the feeling of arousal and pleasure which may result from the cognitive processing and the sense of being in control.

Hence, virtual atmospheric stimuli may induce the cognitive appraisal process, through the dominance. Dominance is a cognitive state that emerges from PAD (pleasure, arousal, dominance) model by Mehrabian and Russell (1974). Adapting the concept of dominance from Russell and Mehrabian (1976), in the current study means the extent that a visitor feels powerful and beliefs in his/her ability to affect a change in a desire direction in the virtual reality retail environment. The loss of control is a precursor to negative affectivity or lack of enthusiasm, but when visitors feels he is in control and thinks about the virtual place where he is, then he will feel wide awake and excited, that is, aroused (Eroglu et al., 2003; Dailey, 2004; Koo \& Lee, 2011; Chang, Chih, Liou, \& Hwang, 2014). Taken all together we suggest the following hypotheses:

$\mathrm{H} 1$ : Atmospheric cues in a virtual reality store is positively associated to dominance.

$\mathrm{H} 2$ : Dominance in a virtual reality store is positively associated to arousal.

H3: Dominance in a virtual reality store is positively associated to pleasure.

$\mathrm{H} 4$ : Arousal in virtual reality store is positively associated to pleasure.

The vividness refers to how much the user can participate in the alteration of form and content of a mediated environment in real time. Together with vividness in virtual worlds there is a simulated presence of virtual air and artificial climate (summer or winter, wind or storms, etc.). Thus, the factor of air quality is replaced by virtual air. Presence or the sense of presence means the possibility to feel to be there in the virtual scenario. The favorable emotional state of pleasure will enrich vividness and presence. Therefore, when a consumer is happy for being in the virtual store, she /he will be more willing to take action in the store and forget their immediate surroundings, being completely immersed, and with the sensation of actual being there (presence) (Mikropoulos, 2006). A positive and immersive virtual store experience will generate emotions that will enhance the sense a presence. Therefore, we suggest the following hypotheses:

H5: Atmospheric cues in a virtual reality store is positively associated to vividness.

H6: Vividness is positively associated to arousal in virtual reality.

H7: Vividness is positively associated to pleasure in virtual reality.

$\mathrm{H} 8$ : Pleasure is positively associated to presence in virtual reality

\section{Methodology}

The virtual model was created using Unity software (version 2017.2.0f3). The virtual environment (VE) simulated a shoes store with which participants could interact. Wall textures were done using simulated shelfs and printed ads of the brand. Additionally, several 3D shelfs with 3D shoes were also used so that participants could explore the shoes while inside the store. The environment was set to have good lighting conditions, a couch and the payment counter. 
All participant started their exploration of the virtual environment at the entrance of the store facing the counter. They could move around in any direction to explore the elements inside the store. The walk-around distance was limited by the cables of the head-mounted VR glasses and by the VE simulated walls.

The sample consisted of 200 individuals, 95 female (corresponding to a percentage of $47.5 \%$ ) and 105 male (corresponding to a percentage of 52.5\%). The ages ranged from 18 to 33 years. All participants were university students, and $11.5 \%$ of those participants identified themselves as "working students". After reading a protocol regarding the use of the material of Virtual Reality (VR), all accepted to participate voluntarily in the study. About fifty-seven percent of the participants had never used Virtual Reality before. A shoe store is selected to be prepared in VR due to the results made in a pre-test with 200 individuals indicating that shoe is a fashion product category that could create equal interest in both genders.

Partial least squares approach is employed to treat data. The adequacy of the measures is assessed by evaluating the reliability of the individual measures, the convergent validity and the discriminant validity of the constructs. After analyzing the measure model, no problem is found, and measures have convergent and discriminant reliability. The repeated indicators method is applied to test the model with second-order formative factors, the atmospheric cues with three factors: ambient factor, design factor and learning factor. Then, the structural model is evaluated (see table 1). All hypotheses are supported, except $\mathrm{H} 2$, which is only supported to 0.10 level.

Findings suggest that a stimulus that remains in the consumers' mind leads to an essential involvement in the creation of cognitive effect (dominance and vividness) leading to positive emotions and, in the end, to enhance the sense of presence. Today's virtual stores are not only accessible to the younger age groups, but they are still the largest and strongest consumer group. The store managers must be aware about how to serve young and stylish consumers, as well as the more traditional ones. Only then, a brand can create an atmosphere that pleases the consumer's perceived and ideal self, leading to enhance presence.

The current study presents some limitations which could also become avenues for future research. First, although the sample is adequate for this type of research, a larger, random sample would provide a deeper and more complex view on the subject.

Second, shoes are chosen after performing a pre-test. But it would be interesting to do the same study with other types of products such as watches for example. It would be interesting to examine the same factors in other contexts to understand whether the results would differ or not. Third, in future the same model could be tested in the presence of different background music styles.

Keywords: atmospheric cues, vividness, virtual reality fashion store, presence, emotions, dominance

Acknowledge: This work was supported by Fundação para a Ciência e a Tecnologia, grant UID/GES/00315/2019 


\section{References}

Areni, C. S. (2003). Examining managers' theories of how atmospheric music affects perception, behaviour and financial performance. Journal of Retailing and Consumer Services, 10(5), 263-274.

Areni, C. S. \& Kim, D. (1993). The influence of background music on shopping behavior: Classical versus top-forty music in a wine store. Advances in Consumer Research, 20, 336-340.

Bellizzi, J. A. \& Hite, R. E. (1992). Environmental color, consumer feelings, and purchase likelihood. Psychology and Marketing, 9(5), 347-363.

Chang, S., Chih, W., Liou, D., \& Hwang, L. (2014). The influence of web aesthetics on customers' PAD. Computers in Human Behavior, 36, 168-178.

Smith, C. A., \& Kirby, L. D. (2009). Putting appraisal in context: Toward a relational model of appraisal and emotion. Cognition and Emotion, 23 (7), 1352-1372.

Dailey, L. (2004). Navigational web atmospherics explaining the influence of restrictive navigation cues. Journal of Business Research, 57, 795-803.

Donovan, R. J., \& Rossiter, J. R. (1982). Store atmosphere: An environmental, psychology approach. Journal of Retailing, 58(1), 34-57.

Eroglu, S. A., Machleit, K. A., \& Davis, L. M. (2003). Empirical testing of a model of online store atmospherics and shopper responses. Psychology \& Marketing, 20(2), 139-150.

Koo, D., \& Lee, J. (2011). Inter-relationships among dominance, energetic and tense arousal, and pleasure, and differences in their impacts under online and offline environment. Computers in Human Behavior, 27, 1740-1750.

Kotler, P. (1974). Atmospherics as a Marketing Tool. Journal of Retailing, 49(4), 4864.

Lazarus, R.S. (1991). Emotion and Adaptation. New York, NY: Oxford University Press.

Loureiro, S.M.C., Almeida, M., \& Rita, P. (2013). The effect of atmospheric cues and involvement on pleasure and relaxation: The spa hotel context. International Journal of Hospitality management, 35(4 December), 35-43.

Loureiro, S.M.C., Guerreiro, J., Eloy, S., Langaro, D., \& Panchapakesan, P. (2018). Understanding the use of Virtual Reality in Marketing: A text mining-based review. Journal of Business Research (published online on 9 November 2018) doi:10.1016/j.jbusres.2018.10.055

Loureiro, S.M.C., Almeida, M., \& Rita, P. (2013). The effect of atmospheric cues and involvement on pleasure and relaxation: The spa hotel context. International Journal of Hospitality management, 35(4 December), 35-43.

Loureiro, S.M.C. \& Roschk, H. (2014). Differential Effects of Atmospheric Cues on Emotions and Loyalty Intention with Respect to Age under Online/Offline Environment. Journal of Retailing and Consumer Services, 21(2), 211-219.

Mattila, A. S. \& Wirtz, J. (2001). Congruency of scent and music as a driver of in-store evaluations and behavior. Journal of Retailing, 77(2), 273-289.

Mehrabian, A., \& Russell, J. A. (1974). An approach to environmental psychology. Cambridge, MA: MIT Press

Michon, R., Chebat, J. C., \& Turley, L. W. (2005). Mall atmospherics: The interaction effects of the mall environment on shopping behavior. Journal of Business Research, 58(5), 576-583.

Mikropoulos, T. A. (2006). Presence: A unique characteristic in educational virtual environments. Virtual Reality, 10(3), 197-206. 
Nah, F. F.-H., Eschenbrenner, B., \& DeWester, D. (2011). Enhancing Brand Equity through Flow and Telepresence: A Comparison of 2D and 3D Virtual Worlds. MIS Quarterly, 35(3), 731-747.

Roschk, H., Loureiro, S.M.C., \& Breitsohl, J. (2017). Calibrating 30 years of experimental research: A meta-analysis of the atmospheric effects of music, scent, and color. Journal of retailing, 93(2), 228-240.

Spangenberg, E. R., Crowley, A. E. \& Henderson, P. W. (1996). Improving the store environment: Do olfactory cues affect evaluations and behaviors? The Journal of Marketing, 60, 67-80

Witmer, B.G., \& Singer, M.J. (1998). Measuring presence in virtual environments: a presence questionnaire. Presence, 7(3), 225-240.

More references upon request

Table 1. Structural results

\begin{tabular}{|c|c|c|c|c|}
\hline Path & Beta & $\begin{array}{l}\text { T Statistics } \\
(\mid \text { O/STDEV } \mid)\end{array}$ & $\begin{array}{c}\mathbf{P} \\
\text { Values } \\
\end{array}$ & Hypothesis \\
\hline $\begin{array}{c}\text { atmospheric cues -> } \\
\text { dominance }\end{array}$ & 0.206 & 2.191 & 0.029 & $\begin{array}{c}\mathrm{H} 1: \\
\text { supported } \\
\text { H2: }\end{array}$ \\
\hline dominance $->$ arousal & 0.147 & 1.676 & 0.094 & $\begin{array}{c}\text { supported for } \\
0.10 \text { level }\end{array}$ \\
\hline dominance $->$ pleasure & 0.210 & 3.160 & 0.002 & $\begin{array}{c}\text { H3: } \\
\text { supported }\end{array}$ \\
\hline arousal $->$ pleasure & 0.380 & 5.488 & 0.000 & $\begin{array}{c}\text { H4: } \\
\text { supported }\end{array}$ \\
\hline $\begin{array}{c}\text { atmospheric cues }-> \\
\text { vividness }\end{array}$ & 0.306 & 3.270 & 0.001 & $\begin{array}{c}\text { H5: } \\
\text { supported }\end{array}$ \\
\hline vividness $->$ arousal & 0.167 & 2.072 & 0.039 & $\begin{array}{c}\text { H6: } \\
\text { supported }\end{array}$ \\
\hline vividness $->$ pleasure & 0.234 & 3.446 & 0.001 & H7:supported \\
\hline pleasure -> presence & 0.524 & 8.814 & 0.000 & $\begin{array}{c}\text { H8: } \\
\text { supported }\end{array}$ \\
\hline Dominance & Vividness & Arousal & leasure & Presence \\
\hline 0.04 & 0.09 & 0.06 & 0.34 & 0.28 \\
\hline
\end{tabular}

